\title{
Effect of captopril on functional mitral regurgitation in dilated heart failure: a randomised double blind placebo controlled trial
}

\author{
Basil Seneviratne, Geoffrey A Moore, Paul D West
}

\begin{abstract}
Objective-To determine the efficacy and dose requirements of captopril to reduce functional mitral regurgitation in patients with dilated heart failure.

Design-A randomised double blind
\end{abstract} placebo controlled parallel arm trial. Incremental daily doses of $25 \mathrm{mg}, 50 \mathrm{mg}$ and $100 \mathrm{mg}$ captopril used for a four week period each for a total of 12 weeks preceded by a two week placebo washout. Twenty eight ambulatory patients (mean age 72) New York Heart Association (NYHA) class II or III with apparently controlled ischaemic dilated heart failure (ejection fraction $29 \%(0.04 \%)$ ) on digoxin, diuretics, and nitrates were randomised. All had at least grade 2/4 functional mitral regurgitation $\left(>5 \mathrm{~cm}^{2}\right.$ regurgitant area on colour flow Doppler). Results-Twenty three patients completed the study (13 on placebo and 10 on captopril). Significant improvements were confined to the captopril group. Compared with placebo the following improvements were noted in the captopril treated group: mitral regurgitant area decreased from a threshold at $\mathbf{5 0}$ mg/day ( $p<0.05$, mean $(95 \%$ confidence interval $(95 \% \mathrm{CI})) 3 \cdot 1(0.2$ to 6.0$\left.) \mathrm{cm}^{2}\right)$, with a further decrease at $100 \mathrm{mg} / \mathrm{day}(p$ $<0.01$, mean $(95 \%$ CI) $5.3(3.1$ to $7 \cdot 5)$ $\left.\mathrm{cm}^{2}\right)$. Significant improvements in all the other measurements were noted only after 100 mg/day. Stroke volume increased ( $p<0.01$, mean $(95 \%$ CI) 11 , $(1.4$ to 21$) \mathrm{ml}$, systemic vascular resistance decreased $(p<0.05$, mean $(95 \% \mathrm{CI})$ 414 (35 to 7.93) dyn s $\mathrm{cm}^{5}$ ), left atrial area decreased ( $p<0.05$, mean $(95 \%$ CI) 4.3 $(0.03$ to 8.6$\left.) \mathrm{cm}^{2}\right)$, and deceleration time increased (p $<0.01$, mean (95\% CI) $52 \mathrm{~ms}$ (7 to 98 ) $\mathrm{ms}$ ). Left ventricular diameter decreased marginally $(p=0.06$, mean (95\% CI) 4 ( -0.05 to $9 \mathrm{~mm})$. Duke activity index score increased $(p<0.001$, median (95\% CI) 6.8 ( 4.5 to 12 ) points). Heart rate, mean arterial blood pressure, serum creatinine, and serum potassium did not change with either placebo or captopril. No patient was withdrawn directly due to the side effects of captopril. In an open phase nine placebo patients given captopril in rapid increments reaching $100 \mathrm{mg} / \mathrm{day}$ in the fourth week showed similar improvements.

Conclusion-Captopril is efficacious in reducing functional mitral regurgitation in dilated heart failure. Patients require and must tolerate high doses (50-100 mg/day) for additive effects over supervised conventional treatment to occur.

(Br Heart $\mathcal{F} 1994 ; 72: 63-68)$

Functional mitral regurgitation is a consistent finding in dilated heart failure ${ }^{1}$ leading to a vicious cycle of ventricular and atrial overload, increase in pulmonary wedge pressure, ${ }^{2}$ and congestive symptoms. Load reduction with vasodilators redirects mitral regurgitation forward both at rest $^{3}$ and after exercise ${ }^{4}$ thereby increasing cardiac output, improving ventricular and atrial geometry with a further decrease in mitral regurgitation. This results in sustained improvement in symptoms. Although the acute haemodynamic effects of the angiotensin converting enzyme (ACE) inhibitor captopril are known, ${ }^{5}$ its ability to reduce functional mitral regurgitation in dilated heart failure has not been investigated in a placebo controlled study. Moreover the optimal dose of captopril for dilated heart failure is unknown and there is a tendency among both British and North American prescribers to use subtherapeutic doses especially in elderly patients for fear of side effects. ${ }^{67}$ Recent evidence suggests that low dose compared with high dose ACE inhibitor treatment is associated with higher mortality. ${ }^{8}$ In our heart failure data bank of 233 cases enrolled over the past two years the overall prevalence of functional mitral regurgitation was $51 \%$, with $37 \%$ having functional mitral regurgitant jets $>5 \mathrm{~cm}^{2}$ on colour flow Doppler (regurgitant grade $2 / 4$ or higher). Yet overall only $9 \cdot 4 \%$ were on high dose ACE inhibitor treatment ( $>50 \mathrm{mg}$ captopril/day or $>10 \mathrm{mg}$ enalapril/day); most were on lower doses. Residual mitral regurgitation may reflect ineffective or inadequate treatment.

By means of colour flow Doppler echocardiography we studied the efficacy and dose requirements of captopril in reducing functional mitral regurgitation. The trial was a randomised double blind placebo controlled parallel arm study on ambulatory patients with dilated heart failure and functional mitral regurgitation.

Patients and methods

Twenty eight ambulatory patients with chronic stable heart failure were enrolled. They had a mean (range) age of 71.6 (57-80)
Australia.

Accepted for publication 20 December 1993 
years and were New York Heart Association (NYHA) grade II or III, with dilated left ventricles (left ventricular end diastolic diameter on $M$ mode $>6 \mathrm{~cm}$ ), ejection fraction $<40 \%$, and a functional mitral regurgitant area $>5$ $\mathrm{cm}^{2}$ on colour flow Doppler. All except one were men. Twenty seven patients had had previous myocardial infarcts and the other had an idiopathic dilated cardiomyopathy. The heart failure was apparently controlled on digoxin, diuretics and nitrates. Four on low dose captopril ( $\leqslant 25 \mathrm{mg} /$ day) and one on enalapril ( $5 \mathrm{mg} /$ day) had their ACE inhibitors withdrawn. Exclusion criteria were myocardial infarction within the preceding three months, unstable or severe angina pectoris, valvar heart disease, serum creatinine $>0.18$ $\mathrm{mmol} / \mathrm{l}$, a history of alcohol misuse, and ACE inhibitor treatment of either $>25 \mathrm{mg}$ of captopril or $>5 \mathrm{mg}$ of enalapril a day. The protocol was approved by the hospital ethics committee and informed consent was obtained from each patient.

PROTOCOL

After a two week placebo washout period each patient was given a test dose of oral captopril $(6.25 \mathrm{mg})$ and blood pressure was monitored for four hours. The patients without hypotension were randomised to active captopril or matching placebo, starting with $6.25 \mathrm{mg}$ twice daily in the first week and after a satisfactory interview the dose was incrementally increased so that each received $12.5 \mathrm{mg}$ twice daily at the end of four weeks, $25 \mathrm{mg}$ twice daily at the end of eight weeks, and $50 \mathrm{mg}$ twice daily at the end of 12 weeks. At each four weekly review, clinical assessment, blood tests for haematology and biochemistry, and cross sectional echocardiography with spectral and colour flow Doppler were performed. Conventional treatment was continued with adjustments to diuretics as required by weight changes. The patients were under constant supervision by a cardiac nurse through home visits and telephone contacts. After completion of the double blind phase, consenting patients on placebo were given open label captopril in incremental doses reaching 100 $\mathrm{mg} /$ day by the fourth week and were reassessed.

\section{INSTRUMENTATION}

An Acuson 128 cardiac colour flow Doppler system with a $2 \cdot 25 \mathrm{MHz}$ transducer for cross sectional imaging and a sample size of $5 \mathrm{~mm}$ for pulsed Doppler analysis was used. All measurements were made by the machine on line computer. Left ventricular end diastolic diameter was measured by cross sectional guided $M$ mode. ${ }^{10}$ The left ventricular outflow stroke integral (LVSI (cm)) was measured by pulsed Doppler sampling in the left ventricular outflow tract from the apical long axis view. Stroke volume $(\mathrm{ml})=$ LVSI $\times 3.14 \times(\mathrm{D} / 2)^{2}$, where $\mathrm{D}=$ left ventricular outflow diameter $(\mathrm{cm})$ at the aortic annulus obtained from the long axis view. ${ }^{11}$ This diameter was assumed to remain constant for the serial measurements. Mitral regurgitation was assessed from the apical four chamber view by measuring the maximal area of the regurgitant jet on colour flow Doppler, ${ }^{12}$ which included the aliasing and non-aliasing jet areas. Equipment settings that included the colour variance maps, frame rate, and depth were kept constant for each patient but gain was optimised to a level just below the point of appearance of noise artefact. Left atrial area was measured with planimetry from the frozen apical four chamber view at end systole. The left ventricular diastolic filling was assessed by sampling transmitral flow at the tip of the mitral valve from an apical four chamber view. ${ }^{13}$ Special emphasis was made on the deceleration time of the early filling (E) wave. A shortened deceleration time is known to be associated with raised filling pressures and high diastolic pressures. ${ }^{14} 15$

\section{DERIVED HAEMODYNAMICS}

Arterial blood pressure (BP) was estimated by cuff sphygmomanometry (Dynamap):

$$
\begin{aligned}
& \mathrm{MAP}=\frac{\mathrm{SBP}-\mathrm{DPB}}{3}+\mathrm{DBP} ; \mathrm{CO}=\mathrm{SV} \times \mathrm{HR} ; \\
& \mathrm{SVR}=\frac{\text { MAP-RAP }}{\mathrm{CO}} \times 80
\end{aligned}
$$

MAP $=$ mean arterial blood pressure $(\mathrm{mm}$ $\mathrm{Hg}) ; \mathrm{SBP}=$ systolic blood pressure $(\mathrm{mm} \mathrm{Hg})$; DBP = diastolic blood pressure $(\mathrm{mm} \mathrm{Hg})$; $\mathrm{CO}=$ cardiac output $(1 / \mathrm{min}), \quad \mathrm{SV}=$ stroke volume $(\mathrm{ml}) ; \mathrm{HR}=$ heart rate (beats $/ \mathrm{min}$ ); SVR = systemic vascular resistance (dyn.s. $\mathrm{cm}^{-5}$ ); RAP = right atrial pressure, which was assumed to be $10 \mathrm{~mm} \mathrm{Hg}$ for all studies.

The Duke activity status index ${ }^{16}$ has been shown to have a reasonable correlation with maximum oxygen consumption at peak exercise and is a good measure of functional capacity. It ranges from a minimum score of 2.75 points for activities of daily living (independence in dressing and bathing) to a cumulative total of 58.2 points for one who is playing strenuous sports. This was assessed at randomisation and at the end of the 12 week study.

\section{WITHIN OBSERVER VARIABILITY}

One investigator, who was blinded, assessed the clinical state and performed all the Doppler echocardiographic studies. Readings were averaged over three cycles for patients in sinus rhythm and over five cardiac cycles for the five patients in atrial fibrillation. The variability of left ventricular stroke volume was assessed at $3 \cdot 1 \%(0-5 \mathrm{ml})$. Within observer variability for mitral regurgitant area was $6 \%$ $\left(0-1 \mathrm{~cm}^{2}\right)$. Day to day variation in mitral regurgitation in dilated cardiomyopathy is known to be about $15 \%$ (NS). ${ }^{17}$ Hence a $>30 \%$ reduction in jet area would be needed to predict a therapeutic response at the level of the $95 \%$ confidence interval $(95 \% \mathrm{CI})$. Twenty two patients completing the study would enable an adequate analysis at the level $\mathrm{p}<0.05$ with $80 \%$ power. 
Table 1 Baseline characteristics (mean (SD)) of patients completing the trial

\begin{tabular}{|c|c|c|c|}
\hline & $\begin{array}{l}\text { Captopril } \\
(n=10)\end{array}$ & $\begin{array}{l}\text { Placebo } \\
(n=13)\end{array}$ & p Value \\
\hline $\begin{array}{l}\text { Age (yr) } \\
\text { Arterial pressure }(\mathrm{mm} \mathrm{Hg}) \\
\text { Duke activity status index } \\
\text { Left ventricular end diastolic diameter }\left(\mathrm{cm}^{2}\right) \\
\text { Mitral regurgitant area }\left(\mathrm{cm}^{2}\right) \\
\text { Stroke volume }(\mathrm{ml}) \\
\text { Systemic vascular resistance }(\text { dyn.s.cm } \\
\text { Left atrial area }\left(\mathrm{cm}^{2}\right) \\
\text { Creatine }(\mathrm{mmol} / \mathrm{l})\end{array}$ & $\begin{array}{c}72 \cdot 3(5 \cdot 4) \\
99(13 \cdot 8) \\
21 \cdot 5(7 \cdot 8) \\
6 \cdot 4(0 \cdot 3) \\
8 \cdot 1(2 \cdot 4) \\
43(9 \cdot 6) \\
2274(573) \\
30 \cdot 1(5 \cdot 5) \\
0 \cdot 13(0 \cdot 02)\end{array}$ & $\begin{array}{c}71 \cdot 5(7 \cdot 2) \\
93(9 \cdot 8) \\
22 \cdot 6(11) \\
6 \cdot 4(0 \cdot 5) \\
9 \cdot 0(2 \cdot 4) \\
42(10 \cdot 4) \\
2257(576) \\
31 \cdot 9(6 \cdot 7) \\
0 \cdot 13(0 \cdot 02)\end{array}$ & $\begin{array}{l}0.77 \text { (NS) } \\
0.17 \text { (NS) } \\
0.91 \text { (NS) } \\
0.47 \text { (NS) } \\
0.25 \text { (NS) } \\
0.49 \text { (NS) } \\
0.96 \text { (NS) } \\
0.42 \text { (NS) } \\
0.93 \text { (NS) }\end{array}$ \\
\hline
\end{tabular}

One patient taking captopril was a woman; three patients taking captopril and two taking placebo were in atrial fibrillation.

\section{STATISTICS}

Within group and between group comparisons were made by one and two way analysis of variance with paired and unpaired Student's $t$ tests as appropriate. The 95\% CIs were calculated. The results of the Duke activity status index were analysed with the Mann-Whitney U test.

\section{Results}

Twenty three patients completed the study (10 on captopril, 13 on placebo, table 1 ). Of the five withdrawals, four were in the captopril and one was in the placebo group. No patient withdrew due to a direct effect of captopril. Two patients were withdrawn by their physicians a few days after randomisation to captopril; one had a recurrence of a severe endogenous depressive illness, another developed an unrelated illness, but both continued to take captopril outside the trial. One on placebo died suddenly after an acute myocardial infarction.

Table 2 Response to captopril v placebo (mean (SD)

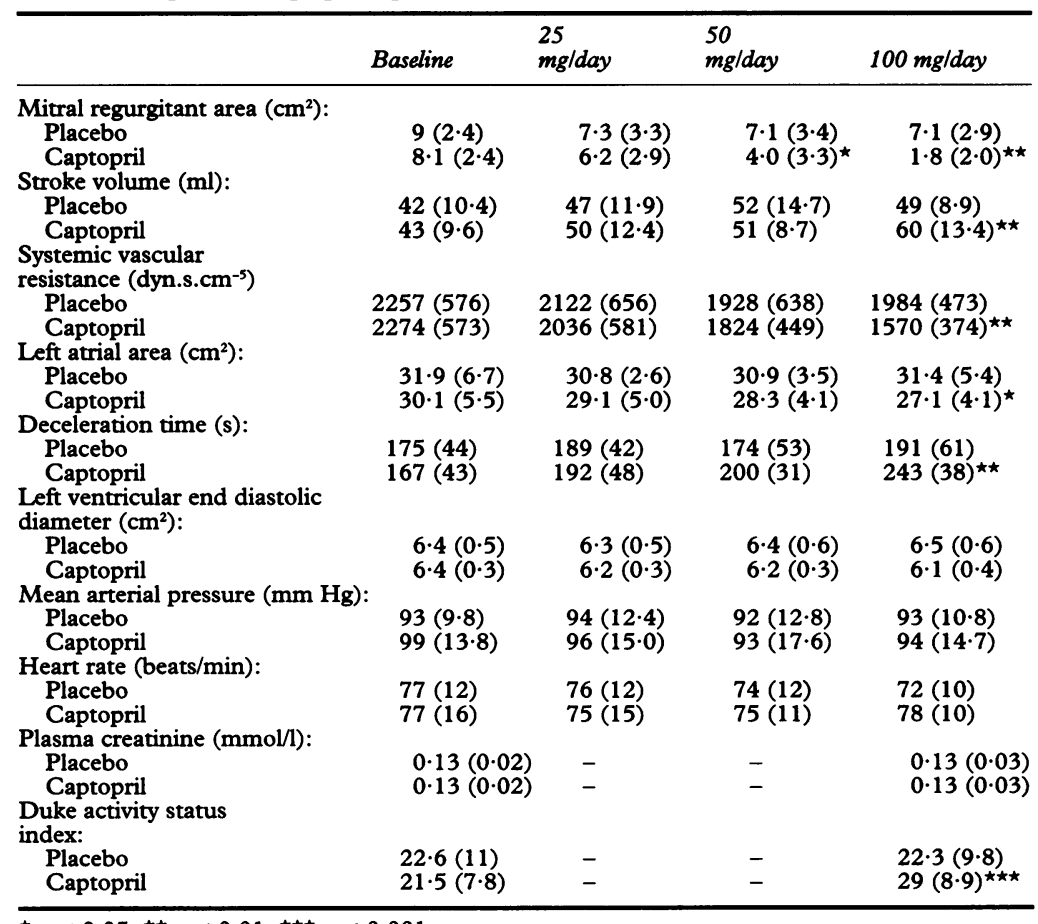

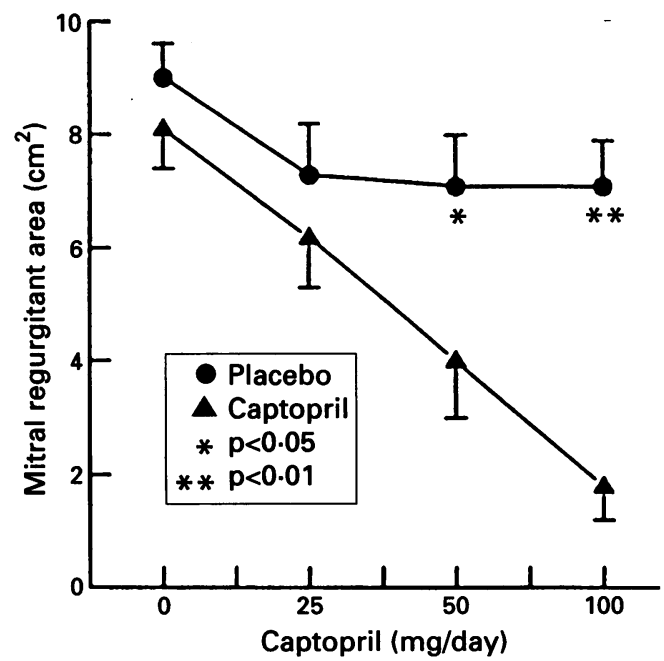

Figure 1 Mital regurgitant area (mean (SEM)) versus captopril dose.

MITRAL REGURGITANT AREA

Table 2 and figure 1 show that mitral regurgitant area did not decrease significantly in the placebo group $(F=1 \cdot 26 ; \mathrm{p}=0 \cdot 29)$ whereas a significant decrease, compared with both baseline and placebo, was found in the captopril group $(F=9.87 ; p<0.001)$. Compared with placebo captopril decreased mitral regurgitation from a threshold dose of $50 \mathrm{mg} /$ day (p < 0.05 ; mean $(95 \% \mathrm{CI}) 3.1(0.2$ to 6$\left.) \mathrm{cm}^{2}\right)$ with a further decrease at $100 \mathrm{mg} /$ day ( $p<0.01$; mean $(95 \%$ CI) 5.3 (3.1 to 7.5 ) $\mathrm{cm}^{2}$ ).

STROKE VOLUME AND SYSTEMIC VASCULAR RESISTANCE

Table 2 and figure 2 show that stroke volume did not increase significantly in the control group $(F=1.92 ; \mathrm{p}=0.01)$ but a significant increase was noted at a threshold of $100 \mathrm{mg}$ of captopril daily $(F=3.64 ; \mathrm{p}<0.02)$.

Differences in favour of captopril compared with placebo were noted only after doses of $100 \mathrm{mg} /$ day ( $<<0.01$; mean (95\% CI) 11

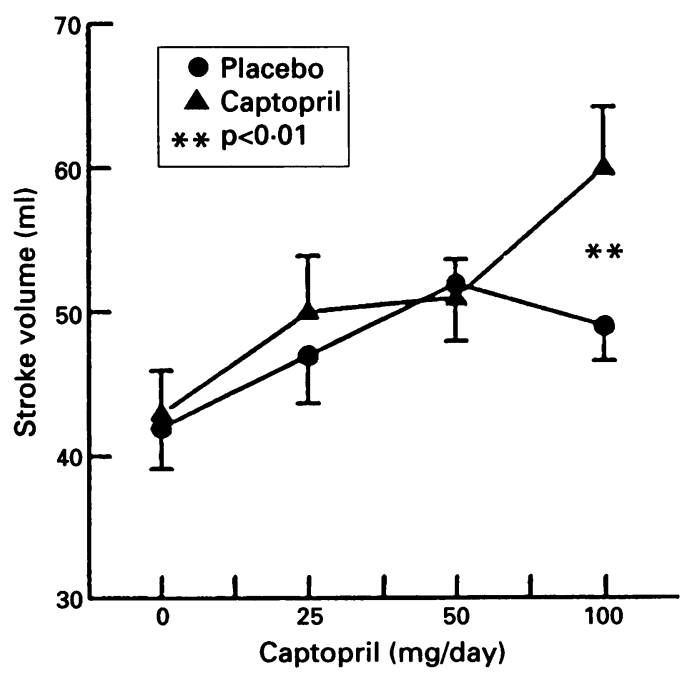

Figure 2 Stroke volume (mean (SEM)) versus captopril dose. 


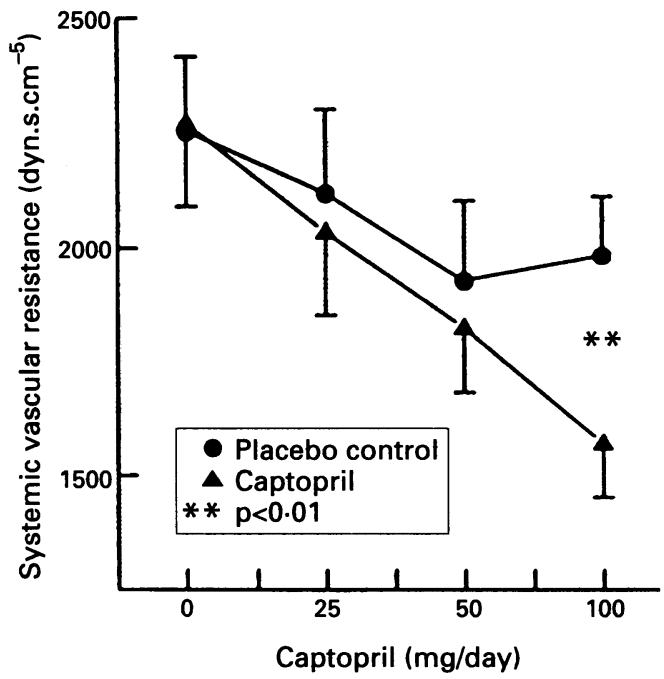

Figure 3 Systemic vascular resistance (mean (SEM)) versus captopril dose.

$(1.4$ to 21$) \mathrm{ml})$. Table 2 and figure 3 show that systemic vascular resistance did not decrease in the placebo group whereas a significant decrease in favour of captopril was noted at $100 \mathrm{mg} /$ day $(\mathrm{p}<0.01$; mean $(95 \% \mathrm{CI}) 414$ (35 to 793) dyn.s.cm ${ }^{-5}$ ).

LEFT ATRIAL AREA

Left atrial area did not decrease with placebo $(\mathrm{F}=0.13 ; \mathrm{p}=0.9)$ but decreased with captopril after the $100 \mathrm{mg} /$ day dose $(\mathrm{p}<0.05$; mean $(95 \% \mathrm{CI}) 4.3(0.03$ to 8.6$) \mathrm{cm}^{2}$ (table 2 , fig 4).

DECELERATION TIME

Table 2 and figure 5 show that the deceleration time of the $\mathrm{E}$ wave did not increase after placebo $(F=0.39 ; \mathrm{p}=0 \cdot 7)$. Significant differences in favour of captopril were seen, marginally after $50 \mathrm{mg} /$ day and maximally at the $100 \mathrm{mg}$ daily dose $(\mathrm{p}<0.01 ;$ mean $(95 \% \mathrm{CI})$ 52 (7 to 98 ) $\mathrm{ms}$ )

LEFT VENTRICULAR END DIASTOLIC DIAMETER Left ventricular diameter did not decrease with placebo $(F=0 \cdot 2)$. Although there was a trend suggesting a decrease after $100 \mathrm{mg} /$ day

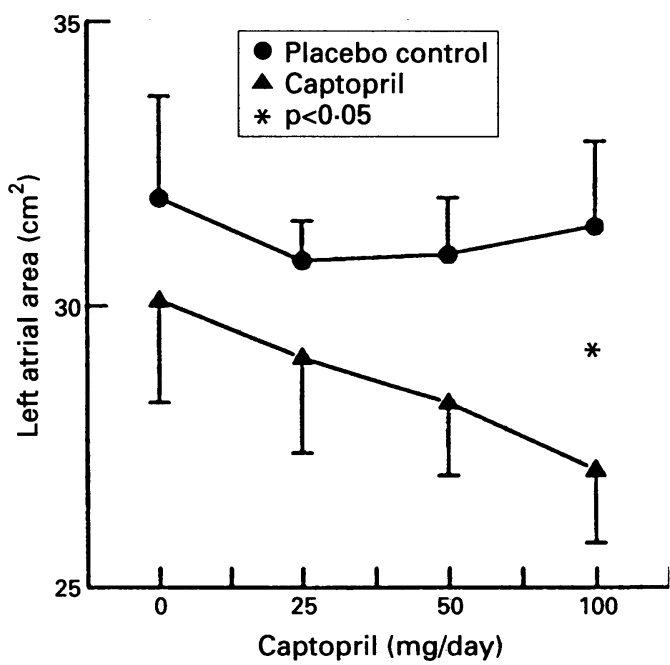

Figure 4 Left atrial area (mean (SEM)) versus captopril dose.

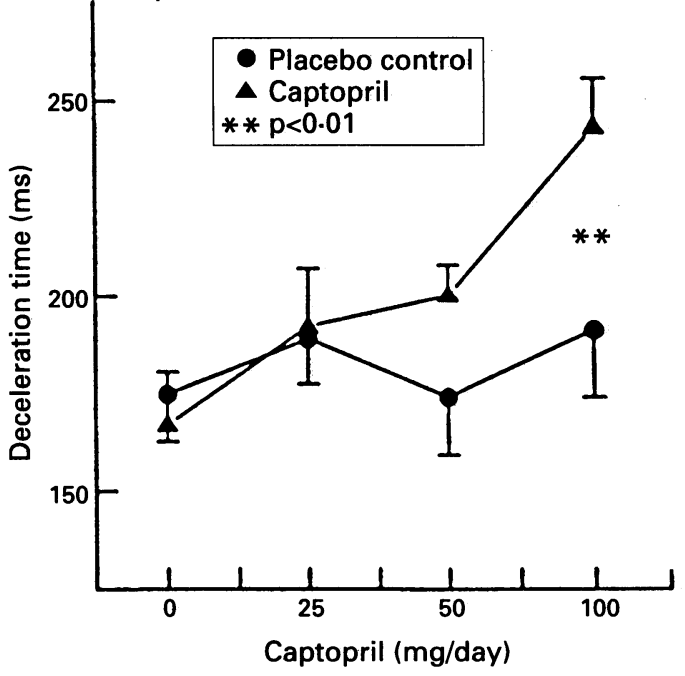

Figure 5 Deceleration time (mean (SEM)) versus captopril dose.

of captopril this did not reach significance $(\mathrm{p}=0.06$; mean $(95 \% \mathrm{CI}) 4(-0.05$ to $9 \mathrm{~mm})$ (table 2).

DUKE ACTIVITY INDEX SCORE

Table 2 and figure 6 show that the Duke activity index score increased by a (median $95 \% \mathrm{CI}$ ) of $6 \cdot 8(4.5$ to 12$)$ points after 100 $\mathrm{mg} /$ day of captopril whereas there was no improvement with placebo (Mann-Whitney U test; $\mathrm{p}<0.001$ ).

Heart rate, systolic blood pressure, mean arterial pressure, serum creatinine, and serum potassium concentrations did not change with either placebo or captopril. Three patients in the placebo group required an increase in diuretic dose to control weight gain. Of the five patients who had their low dose ACE inhibitors withdrawn, three were randomised to placebo and none deteriorated clinically or haemodynamically during the 12 week study.

OPEN PHASE

Nine patients on placebo agreed to take open label captopril given in rapid increments to reach $100 \mathrm{mg} /$ day in four weeks. All nine completed this phase. Mitral regurgitation area decreased $(p<0.002$; mean $(95 \% \mathrm{CI})$ $4.6(3.6$ to $\left.5 \cdot 7) \mathrm{cm}^{2}\right)$. Stroke volume increased $(\mathrm{p}<0.002$; mean $(95 \% \mathrm{CI}) 12(6$ to 19$) \mathrm{ml})$

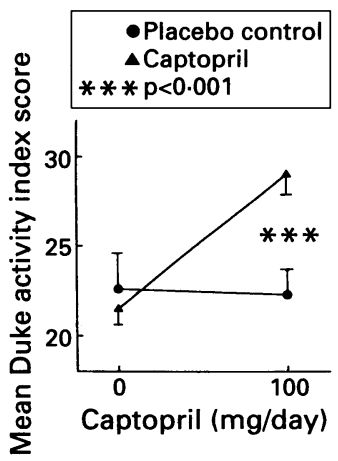

Figure 6 Duke activity index score (mean (SEM)) versus captopril dose. 
Deceleration time increased $(\mathrm{p}<0.03$; mean $(95 \% \mathrm{CI}) 32$ (4 to 61$) \mathrm{ms})$. Systemic vascular resistance decreased $(p<0.09$; mean $(95 \%$ CI 522 (175-870) dyn.s.cm ${ }^{-5}$ ). Duke activity increased $(p<0.01$; mean $(95 \%$ CI) 4.5 $(0 \cdot 9-8 \cdot 1)$ points). The mean arterial pressure, heart rate, systolic blood pressure, left atrial area, and left ventricular end diastolic diameter did not change significantly. These findings are comparable with those obtained on 100 $\mathrm{mg} /$ day at the end of 12 weeks with the exception of the left atrial area.

\section{Discussion}

Our study shows that captopril is efficacious in reducing functional mitral regurgitation in patients with dilated heart failure (with NYHA class II or III symptoms), but a dose of at least $50-100 \mathrm{mg} /$ day is required to show significant additive effects over supervised conventional treatment. These doses, reached by gradual increments, were safe and well tolerated even in an elderly population and there was no reduction in renal function or mean arterial blood pressure. As noted in previous studies the placebo group showed an improvement in some haemodynamics although this was not significant. This improvement may reflect the intense supervision of the cardiac nurse in ensuring drug compliance.

Captopril reduced mitral regurgitant area by $50 \%$ after $50 \mathrm{mg} /$ day and by $77 \%$ after 100 $\mathrm{mg} /$ day whereas placebo caused only a maximum reduction of $21 \%$, which was not significant. Reduction of mitral regurgitation would reduce left ventricular and left atrial loading with decreased left atrial size and decreased left ventricular filling and wedge pressures. A significant reduction in left atrial size was seen after the $100 \mathrm{mg}$ daily dose. A smaller left atrial size resulting from the decrease in size of the atrioventricular orifice would decrease mitral regurgitation further and may prevent or delay the onset of atrial fibrillation. A decrease in left ventricular filling and end diastolic pressure was reflected by a significant lengthening of the deceleration time of the early filling Doppler (E) wave. This signals an easing of the restrictive physiology seen with high filling pressures. ${ }^{14} 15$ At least $100 \mathrm{mg} /$ day was needed to show significant increases in stroke volume and reduction in systemic vascular resistance. The Duke activity status index score improved by an average of 6.9 points with captopril at the end of 12 weeks whereas there was no improvement with placebo $(p<0.001)$. This could be translated to an improvement in a patient who was once limited to light work in the house being able to do moderate work, such as carrying groceries and working in the garden.

Left ventricular diameter decreased with captopril but this did not reach significance $(p$ $=0.06$ ). Previous work has shown a reduction in left ventricular volume after reduction in mitral regurgitation with vasodilator treatment. ${ }^{3}$ Measurement by $M$ mode would be too insensitive to show changes in left ventricular volume. Recently the studies of left ventricular dysfunction (SOLVD) group showed by ventriculography that long-term enalapril treatment resulted in a sustained reduction in left ventricular volume whereas there were progressive increases in left ventricular volume in the placebo treated group. ${ }^{18}$ The mechanism of this effect was not clear. It is tempting to postulate that, among other effects, ACE inhibitor treatment may have reduced the functional mitral regurgitation common in NYHA class II and III heart failure.

The presence of functional mitral regurgitation in congestive heart failure is, we believe, a marker of clinical importance. It identifies a group of patients most likely to benefit from vasodilator treatment. ${ }^{19}$ In patients, as our study group, already on conventional treatment or taking low dose ACE inhibitors its presence indicates inadequacy of treatment for load reduction. Based on the premise that vasodilators redirect regurgitant flow to increase forward stroke volume, increasing the dose of vasodilators would lead to increased cardiac output without a drop in mean arterial pressure, as was found in our study. Patients with dilated heart failure do not necessarily require high filling pressures to maintain cardiac output; they could function well at normal filing pressures. ${ }^{20}$ Hence aggressive treatment is both safe and warranted.

Although the acute haemodynamic effects of captopril are independent of dose $(12.5-100 \mathrm{mg})$ they do not predict the longterm response. ${ }^{21}$ A sustained effect depends on a relatively high dose that is the cornerstone of chronic treatment. ${ }^{22}$ Exercise capacity improves gradually over four to six weeks after fixed doses of captopril. To make allowances for this time effect each dose period was four weeks in our study. Hence the haemodynamic changes at the end of four weeks would be a valid reflection of the effects of the respective doses. There was no improvement in any of the measurements at the fourth week (25 $\mathrm{mg} /$ day) and even after eight weeks (50 $\mathrm{mg} /$ day) improvements in mitral regurgitation and deceleration time were only just perceptible. Yet in the open phase trial significant improvements were noted in four weeks (100 $\mathrm{mg} /$ day) comparable with those seen at 12 weeks in the graded study. Of three patients who had their low dose ACE inhibitors withdrawn and who were randomised to placebo, none deteriorated clinically or haemodynamically after 12 weeks. Although this is not absolute proof, these data support the importance of dose overriding time, but it is still conceivable that the lower dose $(50 \mathrm{mg} /$ day $)$ given over a longer period than eight weeks could lead to further improvement. Hence a larger trial is now planned to compare 50 $\mathrm{mg} /$ day with $100 \mathrm{mg} /$ day captopril in a similar group of patients over 16 weeks. This will also reduce the inherent risk of type 2 error as in our current study where the numbers were smaller. 


\section{LIMITATIONS}

Our findings on dose requirements of captopril would be applicable to patients with dilated heart failure and functional mitral regurgitation; the optimal dose requirements of patients with less left ventricular dysfunction may well be lower. The assessment of mitral regurgitation by colour flow Doppler is semi-quantitative and the regurgitant area reflects the free jet momentum (incorporating the driving force and the flow rate) and to a lesser extent left atrial compliance, assuming that machine factors are kept constant. All our patients had central free jets best seen in the apical view and the equipment settings were kept constant for serial studies. The driving force may have actually increased as the blood pressure remained unchanged and the left atrial pressure was presumed to have decreased. Hence a reduction in the regurgitant area would indicate a decrease in flow rate and volume. Recent work has shown that colour flow imaging of jet areas are valid for quantitative assessment of mitral regurgitation in ischaemic or functional regurgitation where the jets are almost always central. ${ }^{23}$ The Doppler measurement of stroke volume has been previously validated ${ }^{11}$; the errors in measurement of the left ventricular outflow diameter were minimised by assuming that the diameter remains constant in the serial studies. Although the combination of a shortened left ventricular isovolumetric relaxation time, shortened deceleration time of the $\mathrm{E}$ wave, and an increased E/A (early to atrial filling) ratio best predicts increased left ventricular filling pressures ${ }^{15}$ we chose to use only the deceleration time as we have found this to be the easiest and the most reproducible to record. A long deceleration time reflected a fall in filling pressures and is known to be independent of the degree of mitral regurgitation. ${ }^{15}$ The singular value of deceleration time in assessing left ventricular filling pressures in the presence of left ventricular dysfunction has been emphasised recently. ${ }^{24}$

In conclusion captopril reduces functional mitral regurgitation in dilated heart failure when given in adequate doses (50-100 $\mathrm{mg} /$ day). Residual mitral regurgitation in patients with heart failure may be a marker of suboptimal treatment. Such patients may form a sizeable proportion in outpatient clinics and they need and tolerate large dose treatment even if they are elderly. We confirm that Doppler echocardiography is a valuable method to detect mitral regurgitation, which is often silent, and is useful to monitor the haemodynamic response and titrate treatment in patients with dilated heart failure. ${ }^{25}$

We thank the physicians and cardiologists who referred cases, the hospital pharmacists, and the technical staff of the noninvasive laboratory. Our thanks to our cardiac nurse Mrs Suzanne Timmins and to Mrs Sirikku Thilonius for typing the manuscript. This study was conducted with the aid of a grant from Bristol-Squibb-Myers who played no part in the analysis and interpretation of the data.
1 Strauss RH, Stevenson LW, Dadourian BA, Child JS Predictability of mitral regurgitation detected by Doppler echocardiography in patients referred for cardiac transplantation, Am $\mathcal{F}$ Cardiol 1987;59:892-4.

2 Vanoverschelde JLJ, Raphael DA, Robert AR, Cosyns JR. Left ventricular filling in dilated cardiomyopathy: relation to functional class and haemodynamics. $\mathcal{F} \mathrm{Am} \mathrm{Coll}$ Cardiol 1990;15:1288-95.

3 Stevenson LW, Belil D, Grove-McKay M, et al. Effects of afterload reduction (diuretics and vasodilators) on left ventricular volume and mitral regurgitation in severe congestive heart failure secondary to ischaemic or idiopathic

4 Stevenson LW, Brunken RC, Belil D, et al. Afterload reduction with vasodilators and diuretics decreases reduction with vasodilators and diuretics decreases mitral regurgitation during upright exercise in a

5 Ader R, Chaterjee K, Ports T, et al. Immediate and sustained haemodynamic and clinical improvement in chronic heart failure by an oral angiotensin converting enzyme inhibitor. Circulation 1980;61:931-7.

6 Poole-Wilson PA, Lindsay D. [Editorial.] BMF 1992;304: 1069-70.

7 Cohn JN. The prevention of heart failure-a new agenda. N Engl F Med 1992;327:725-7.

8 Packer R, Globits S, Bergler-Klein J, et al. Clinical and neurohumoral response of patients with severe congestive cardiac failure, treatment with two different captopril dosages [abstract]. F $\mathrm{Am}$ Coll Cardiol 1992;19: 317A.

9 Quinones MA, Waggoner AD, Reduto LA, et al. A new simplified and accurate method for determining ejection fraction with two-dimensional echocardiography, Circulation 1981;64:744-53.

10 Sahn DJ, DeMaria A, Kisslo J, Weyman A. Recommendations regarding quantitation in $M$-mode echocardiography: results of a survey of echocardioechocardiography: results of a survey of echocard
graphic measurements, Circulation 1978;58:1072-83.

11 Lewis JF, Kuo LC, Nelson JG, Limbacher MC, Quinones MA. Pulsed Doppler echocardiographic determination of stroke volume and cardiac output: clinical validation of two new methods using the apical window. Circulation of two new methods

12 Helemke FH, Nanda NC, Hsiung MC, et al. Color Doppler assessment of mitral regurgitation with orthogonal planes. Circulation 1987;75:175-83.

13 Hatle L, Angelsen B. Doppler ultrasound in cardiology: physical principles and clinical applications, 2nd ed. Philadelphia: Lea and Febiger, 1985, 186.

14 Appleton CP, Hatle LK, Popp RL. Relation of transmitral flow velocity patterns to left ventricular diastolic function: new insights from a combined haemodynamic and Doppler study. $\mathcal{A m}$ Coll Cardiol 1988;12:426-40

15 Mulvagh S, Quinones MA, Kleinman NS, Jorge Cheiruf B, Zoghbi NA. Estimation of left ventricular pressure from Doppler transmitral flow velocity in cardiac patients independent of systolic performance. $7 \mathrm{Am} \mathrm{Coll}$ Cardiol 1992;20:112-9.

16 Hlatky MA, Boineau RE, Higginbotham MB, et al. A brief self-administered questionnaire to determine functional capacity (the Duke activity status index). $7 \mathrm{Am}$ Coll Cardiol 1989;14:651-4.

17 Grayburn PA, Pryor SL, Levine BD, et al. Day to day variability of colour flow jets in mitral regurgitation. $\mathrm{f} \mathrm{Am}$ Coll Cardiol 1989;14:936-40.

18 Konstan MA, Rousseau MF, Kronenberg MW, et al. Effects of the angiotensin converting enzyme inhibitor enalapril on the long term progression of left ventricular dysfunction in patients with heart failure. Circulation dysfunction in

19 Weiland DS, Konstam MA, Salem DN, et al. Contribution of reduced mitral regurgitant volume to Contribution of reduced mitral regurgitant volume to vasodilator effect in severe left ventricular failure secondary to coronary artery disease or idiopathic

20 Stevenson LW, Tillisch JH. Maintenance of cardiac output with normal filling pressures in patients with dilated heart failure. Circulation 1986;74:1303-8.

21 Sharpe DN, Coxon RJ, Douglas JE, Long B. Low dose captopril in chronic heart failure: acute haemodynamic effects and long term treatment. Lancet 1980;ii:1152-4.

22 Levine TB, Franciosa JA, Cohn JN. Acute and long-term response to an oral angiotensin converting enzyme inhibitor, captopril, in congestive heart failure. Circulation 1980;62:35-41.

23 Enriquez-Sarano M, Tajik AJ, Bailey KR, Seward JB. Colour flow imaging compared with quantitative Doppler assessment of severity of mitral regurgitation: influence of eccentricity of jet and mechanism of regurgitation. ₹ Am Coll Cardiol 1993;21:1211-9.

24 Yamamoto $\mathrm{K}$, Masuyama T, Tanouchi J, et al. Importance of left ventricular minimal pressure as a determinant of transmitral flow velocity pattern in the presence of left transmitral flow velocity pattern in the presence of left 1993;21:662-72.

25 Hamilton MA, Stevenson LW, Child JS. Acute reduction of atrial overload during vasodilator and diuretic therapy in advanced congestive heart failure. Am $\mathcal{F}$ Cardiol 1990;65:1209-12. 